\title{
Microcycle Conidiation in Cercospora zeae-maydis
}

\author{
Carrie L. Lapaire and Larry D. Dunkle
}

First author: Department of Botany and Plant Pathology: and second author: Crop Production and Pest Control Research, U.S. Department of Agriculture-Agricultural Research Service, Purdue University, West Lafayette, IN 47907.

Accepted for publication 25 September 2002.

\begin{abstract}
Lapaire, C. L., and Dunkle, L. D. 2003. Microcycle conidiation in Cercospora zeae-maydis. Phytopathology 93:193-199.

Conidia of Cercospora zeae-maydis are the primary inoculum causing gray leaf spot of maize. On nutrient-deficient substrates, but not on water on the leaf surface, conidia germinate and develop secondary conidia on conidiophores produced from germ tubes or conidial cells. A population of conidia increases its numbers more than twofold by 2 days on the surface of a water droplet and by fourfold on trichomes. This microcycle conidiation is suppressed by hydrogen peroxide and ammonium compounds but not by nitrate compounds, amino acids, or simple sugars. Microcycle conidiation is sensitive to $\alpha$-amanitin and cyclohexi-

mide, suggesting that new RNA and proteins must be synthesized. Upon transfer from a humid to a dry atmosphere, secondary conidia and conidiophores dehydrate and collapse. Mature, dehydrated, secondary conidia are liberated by wind speeds approximately one-third those required to liberate hydrated conidia. The dispersed secondary conidia can rehydrate and germinate normally. Because this microcycle conidiation occurs at the expense of endogenous reserves, the ability to produce secondary conidia is lost after four successive cycles without a period of growth on nutrient media. This alternative method of maintaining inoculum potential during periods of fluctuating relative humidity may have epidemiological consequences when primary conidia fail to infect.
\end{abstract}

Cercospora zeae-maydis Tehon \& E.Y. Daniels causes gray leaf spot of maize throughout the maize-growing regions of the United States and Africa $(18,27,43)$. The disease has also been reported in China, South America, and Central America (44). First reported in Illinois in 1925 (39), gray leaf spot increased in severity starting in the mid-1970s as no-till practices were instituted for soil conservation measures $(8,15,44)$. Conservation tillage favors the survival of the pathogen because $C$. zeae-maydis overseasons on crop debris $(14,31)$. In fields where full tillage is practiced, the fungus is exposed to soil microorganisms that out compete it (32). Gray leaf spot is one of the most destructive foliar diseases of maize, significantly reducing yields in many maize-growing areas throughout the world (44). In severely affected regions, yield losses are estimated to be 10 to $25 \%$ annually, but losses as much as $90 \%$ due to severe deterioration of the leaves and stalk lodging have been recorded (27).

The disease cycle of gray leaf spot begins in the spring with conidia produced from the surviving pathogen in lesions on crop debris remaining on the soil surface (32). The conidia are primarily wind-dispersed (44). Stomatal penetration, vegetative growth, and production of new conidia from stroma within the leaf lesion require 14 to 28 days in the field or greenhouse under favorable conditions $(7,8,44)$. Developing lesions progress from tan flecks with chlorotic borders to long, narrow, brown lesions whose width is restricted by major veins. Upon sporulation of the fungus, the lesions become grayish due to the accumulation of spores on the surface. The new conidia are spread by wind and

Corresponding author: L. D. Dunkle; E-mail address: dunkle@ purdue.edu

Names are necessary to report factually on available data. However, the USDA neither guarantees nor warrants the standard of the product, and the use of the names implies no approval of the product to the exclusion of others that may also be suitable.

Publication no. P-2002-1122-02R

This article is in the public domain and not copyrightable. It may be freely reprinted with customary crediting of the source. The American Phytopathological Society, 2003. rain to other leaves and plants, causing secondary infections throughout the growing season. C. zeae-maydis and many other Cercospora species produce cercosporin, a phytotoxin that has been suggested as a virulence factor $(13,22)$. In the light, cercosporin generates active oxygen species that damage the plant cell membrane (13). Other conditions that favor disease development include extended periods of high relative humidity and dew $(7,36)$.

Conidia of many fungal species may use microcycle conidiation as a survival mechanism when conditions are unfavorable for vegetative growth. Hanlin (23) and Smith et al. (37) described microcycle conidiation as the production of spores following conidial germination without an intervening phase of vegetative growth. Microcycle conidiation has been described in more than 100 fungal species (23) including plant pathogens $C$. beticola (33), C. kikuchii (19), and Claviceps sorghi (6). In C. beticola, secondary conidia penetrated host stomata as efficiently as the original primary conidia (33). Thus, spores produced by microcycle conidiation may serve as an important source of inoculum. The phenomenon is often induced by stressful environmental conditions (19,34,35,38). Anderson and Smith (1) observed the phenomenon in Aspergillus niger after subjecting conidia to heat stress. Cortat and Turian (12) and Rossier et al. (34) observed microcycle conidiation in Neurospora crassa after exposing conidia to constant agitation in nutrient-poor liquid media. In studies of fungal reproduction, the ability to induce microcycle conidiation permits synchronization of sporulation and detailed investigation of factors influencing the process.

Production of secondary inoculum by plant pathogenic fungi is significant only if there is a mechanism for liberation and dispersal of secondary conidia. The method of detachment in passively liberated spores is intimately related to the method of dispersion. Conidia of passively detached spores tend to be produced above the substratum on conidiophores, positioning them for wind dispersal (25). Conidia of Cercospora species are borne on erect conidiophores above the leaf surface. These conidia may be raised above the boundary layer of nonturbulent air at the leaf surface and into the layer of turbulent air above the surface (29). 
Gregory and Lacey (21) also suggested that increasing wind speed decreases the thickness of the boundary layer of air at the leaf surface, which would result in the dispersal of more conidia.

Characterization of sporulation and dispersal will contribute important information to the understanding of disease epidemiology and may lead to improved control strategies for gray leaf spot. The objectives of this study were to characterize microcycle conidiation in three main areas: (i) factors that influence microcycle conidiation; (ii) characteristics of detachment; and (iii) factors that influence dispersal of secondary conidia. Here, we describe the process of microcyclic spore production in $C$. zeaemaydis and the epidemiological implications of this alternative source of inoculum.

\section{MATERIALS AND METHODS}

Fungal isolates, conidiation, and growth. Conidia from two isolates of $C$. zeae-maydis were used throughout the study: (i) $\mathrm{SCOH}$ 1-5 from South Charleston, OH; and (ii) SHIL 14B from Sheridan, IL. Cultures were maintained on V8 juice agar (41) and incubated at $25^{\circ} \mathrm{C}$ under a 14 -h light and 10 -h dark cycle. Conidia from sections of the cultures with high spore density were transferred directly onto V8 and harvested after 2 to 4 days for use in all experiments.

Reproductive index. The reproductive index (RI) is used herein as a measurement of inoculum potential. RI is equal to the number of secondary conidia produced divided by the number of original conidia applied to the substrate. RI = (secondary conidia)/(original conidia). Thus, an RI of four indicates that, in a population of conidia, four secondary conidia were produced by each original conidium for a given treatment. Secondary conidia were distinguished from primary conidia by their attachment to conidiophores. Primary conidia gave rise to germ tubes and conidiophores from conidial cells, whereas secondary conidia were attached only to conidiophores and the point of attachment was easily determined. In general, secondary conidia remained attached to the conidiophore for at least 4 days, especially in a humid atmosphere. The mean RI was calculated for each treatment in all experiments that required a measurement of reproductive potential.

Experimental design. For the experiments described below, all treatments included three replicates, and unless indicated otherwise, 100 to 200 original conidia in each replicate were counted and scored for the number of secondary conidia produced. Data were expressed as the mean RI of the three replicates. All experiments were repeated at least once with identical trends and similar numerical results. The mean RI among repeated experiments differed by $<0.3$ unit.

Development on various substrata. To assess the effects of various substrata on microcycle conidiation, conidia were applied directly to $20-\mu \mathrm{l}$ water droplets, dry slides, $2 \%$ water agar, or trichomes on leaf segments of maize. All were maintained in a humid environment. Every $24 \mathrm{~h}$ for 4 days, at least 150 original conidia incubated on each of the three substrates or 50 conidia on trichomes of three maize leaf segments were counted and scored for the number of secondary conidia produced. Data were expressed as the mean RI of the three replicates. In separate experiments, to confirm the ability to produce conidia on leaf trichomes and determine the potential specificity of host plant, trichomes on segments of leaves from soybean (Glycine max), johnsongrass (Sorghum halepense), or giant foxtail (Setaria faberi) were inoculated with conidia and incubated as above.

Exogenous nutrients. To study the effects of water-soluble compounds on the leaf surface on microcycle conidiation, upper surfaces of corn leaves approximately 10 to $15 \times 50$ to $70 \mathrm{~cm}$ collected from the Purdue Agronomy Farm, West Lafayette, IN, were rinsed with $20 \mathrm{ml}$ of distilled water, which was collected and filtered through a $0.2-\mu \mathrm{m}$ syringe filter. Conidia were applied directly to $20-\mu \mathrm{l}$ droplets of the leaf washes. Data were recorded at 2 days postinoculation and expressed as the mean RI from 100 to 150 original conidia in each of three replicates. The leaf washings were assayed for the presence of carbohydrates and amino compounds by the phenol-sulfuric (17) and ninhydrin (45) assays, respectively.

Conidia also were applied directly to $20-\mu$ d droplets containing various compounds and incubated on glass slides in sealed moist chambers at $25^{\circ} \mathrm{C}$. Solutions tested included: $0.25,0.5$, and $2.5 \mathrm{mM} \mathrm{NH} \mathrm{N}_{4} \mathrm{Cl}, \mathrm{K}_{2} \mathrm{SO}_{4}, \mathrm{KNO}_{3}$, or $\left(\mathrm{NH}_{4}\right)_{2} \mathrm{SO}_{4} ; 5$ and $10 \mathrm{mM}$ galactose, glucose, mannitol, mannose, or sucrose; $0.25,0.5$, and $2.5 \mathrm{mM}$ arginine, alanine, glutamine, glutamate, glycine, histidine, lysine, or proline (adjusted to $\mathrm{pH} 6$ to 7). To assess the effect of hydrogen peroxide, conidia were applied directly to $20-\mu$ ldroplets of $1,3,5,10$, or $50 \mathrm{mM} \mathrm{H} \mathrm{H}_{2}$. The ability of catalase (from bovine liver; Sigma Chemical Co., St. Louis) and peroxidase (horseradish; Sigma Chemical Co.) to reverse the effects of hydrogen peroxide and the leaf wash on microcycle conidiation was determined by adding 0.2 units of the enzyme to the droplet. Data were expressed as the mean RI calculated from three replicates of each treatment.

To assess requirements for synthesis of new RNA and proteins, conidia were applied to $20-\mu \mathrm{l}$ water droplets, and $\alpha$-amanitin, an inhibitor of messenger (m) RNA synthesis, or cycloheximide, an inhibitor of protein synthesis, was added to give a final concentration of $50 \mu \mathrm{g} / \mathrm{ml}$ or $10 \mu \mathrm{g} / \mathrm{ml}$, respectively, at $0,1,2,4,6,8,12$, and $24 \mathrm{~h}$ after conidia were deposited on the droplet. Data were collected at $48 \mathrm{~h}$ postinoculation and expressed as the mean RI from the three replicates.

To determine the effect of nutrient starvation, conidia were transferred from V8 plates directly to $2 \%$ water agar (Difco Laboratories, Detroit) plates. These conidia were incubated for 4 days, and germination and secondary conidiation were counted for 50 to 100 conidia in five random fields of view. The secondary conidia were transferred to another water agar plate. Three plates of water agar were used for each generation of newly produced conidia. This process was repeated three times for a total of four generations of secondary conidia produced via microcycle conidiation.

Dehydration and detachment of secondary spores. The effect of intermittent periods of dryness on microcycle conidiation was assessed with conidia removed from a sporulating culture with a platinum needle and applied directly to trichomes of maize and soybean leaf pieces. The leaf pieces were incubated in glass petri dishes with moistened Whatman filter paper. Three dishes were left uncovered and the filter paper was allowed to dry; three dishes were covered to maintain a humid environment; and three dishes were covered for the first $8 \mathrm{~h}$, uncovered overnight, then the filter paper was moistened again and the plates were covered for $8 \mathrm{~h}$. All dishes were incubated at room temperature $\left(23\right.$ to $\left.25^{\circ} \mathrm{C}\right)$. Data were collected at 24 and $48 \mathrm{~h}$ postinoculation and expressed as the mean RI from 100 to 150 conidia in each petri dish.

In a modification of that procedure, conidia were removed from a V8 plate with a platinum needle and applied directly to a $40-\mu \mathrm{l}$ droplet of water on a well slide. The droplet was allowed to evaporate at room temperature overnight. After $8 \mathrm{~h}, 40 \mu \mathrm{l}$ of water were pipetted over the area occupied by conidia, and the spores were allowed to rehydrate for $8 \mathrm{~h}$. The droplet was again allowed to evaporate overnight. This process was repeated for a total of three cycles of dehydration. Data were collected at the end of each rehydration period.

The effects of various relative humidities were studied in sealed chambers $(11.5 \times 8 \times 6 \mathrm{~cm})$ containing $150 \mathrm{ml}$ of saturated salt solutions (41) to provide the following relative humidities: $\mathrm{NaCr}_{2} \mathrm{O}_{7}$ (54\% relative humidity), $\mathrm{NaNO}_{3}$ (74\% relative humidity), $\left(\mathrm{NH}_{4}\right)_{2} \mathrm{SO}_{4}\left(80 \%\right.$ relative humidity), $\mathrm{KNO}_{3}(92 \%$ relative humidity), $\mathrm{K}_{2} \mathrm{SO}_{4}$ (97\% relative humidity), and $\mathrm{H}_{2} \mathrm{O}(100 \%$ relative humidity). Slides with conidia on droplets of water were 
supported above the salt solutions. Data on germination and microcycle conidiation were recorded 3 days postinoculation and expressed as mean RI of three replicates of each relative humidity.

A similar study investigated the number of secondary conidia produced under a regimen of intermittent $100 \%$ relative humidity. Conidia were applied directly to the surface of a sterile, dry, glass slide. The slides were placed in sealed chambers (as above) with relative humidity maintained at $100 \%$ (with water) or $80 \%$ [with $\left(\mathrm{NH}_{4}\right)_{2} \mathrm{SO}_{4}$ ]. After 2 days, data were recorded and three of the six slides which were initially incubated in $100 \%$ relative humidity were shifted to $80 \%$ relative humidity. At 4 days, data were recorded on all slides again, and the three slides that had been shifted to $80 \%$ relative humidity were returned to $100 \%$ relative humidity. After an additional 2 days, data were recorded again on the three slides that had been shifted to $100 \%$ relative humidity, and the experiment was terminated.

Detachment of conidia by wind. Studies of detachment of conidia from their conidiophores were conducted by applying an air stream across a slide that had been inoculated with conidia. Spores were applied to water droplets and incubated in a moist chamber for 4 days. The slides were removed from the moist chambers and viewed at $\times 40$ with a light microscope while a gentle air stream from the laboratory air supply was directed through rubber tubing and a Pasteur pipette across the slide. Another set of slides with inoculated droplets was allowed to dry at room temperature, and an air stream was directed across the slide and desiccated spores. Velocity of the air required to detach conidia from the conidiophores was recorded with an anemometer (Model DA40; Pacer Industries, Inc., Chippewa Falls, WI). The wind speed was recorded when 10 to $20 \%$ of spores were detached from their conidiophores. Three individual replicates were included in each measurement. Observations relating maturity (size and septation) of secondary conidia to detachment were also recorded.

To assess the viability of secondary conidia, a third set of slides with desiccated spores was positioned perpendicular to a water agar surface. An air stream was directed across the slide, dislodging the secondary conidia. Conidia were collected on the water agar surface to assess hydration, germination, and microcycle conidiation.

Cryo-scanning electron microscopy preparation. Sections of V8 culture with high spore density were inverted over maize leaves and touched gently to apply conidia directly to maize trichomes on leaf pieces. The leaf pieces were incubated for $24 \mathrm{~h}$ at $25^{\circ} \mathrm{C}$. A 6-mm-diameter cork borer was used to cut sections of the leaves for use in the scanning electron microscope. Samples were frozen by plunging into $\mathrm{N}_{2}$ slush and sputter-coated for 4 min with gold in the presence of argon at $-160^{\circ} \mathrm{C}$ and $2 \mathrm{~mA}$ current. Samples were viewed at $-140^{\circ} \mathrm{C}$ in a JEOL JSM-840 SEM with $5 \mathrm{kV}$ accelerating voltage.

Light microscopy. Conidia were applied directly to $20-\mu$ water droplets on glass slides and incubated for 24 or $48 \mathrm{~h}$ at $25^{\circ} \mathrm{C}$. Coverslips were placed over droplets after incubation. The conidia were observed through a $\times 16$ and a $\times 40$ lens of a Zeiss differential interference contrast microscope and photographed with a Nikon AFX-DX on tungsten film (Kodak Ektachrome 64T).

\section{RESULTS}

Production of secondary conidia. Within 4 days, conidia of $C$. zeae-maydis germinated and produced an average of four secondary conidia on trichomes of maize (Fig. 1), soybean, johnsongrass, and foxtail, on a water droplet, or the surface of water agar. Secondary conidia were formed within $24 \mathrm{~h}$ on the surface of a droplet of water. Conidia that submerged beneath the surface of a droplet germinated but did not produce conidia. Olivaceous conidiophores arose from conidial cells or germ tubes (Fig. 2). The conidiophores were easily distinguished from germ tubes by their pigmentation, multiple septa at regular intervals, and their formation at right angles to the germ tube. Mature original and secondary conidia were hyaline and had one or more septa.

Although microcycle conidiation did not require a nutrient source, the process was found to be nutrient-limited on all nutrient-poor substrata. Four successive generations of secondary conidia were produced before the ability to undergo microcycle conidiation was lost in the fifth generation of secondary conidia. Although the majority of conidia continued to germinate after the fourth generation, germinating conidia were vacuolated, and germ tubes were thin and ceased to elongate after reaching a length of 30 to $40 \mu \mathrm{m}$.

Secondary conidia usually were smaller than the original conidia. However, even after several generations of growth on nutrientpoor substrates such as water or water agar, the dimensions of the conidia were within the range characteristic of $C$. zeae-maydis $(11,39)$. When defining the characteristics of $C$. zeae-maydis conidia, Chupp (11) noted that length of conidia differs with environmental conditions indicating that many factors may influence length and overall size of secondary conidia.

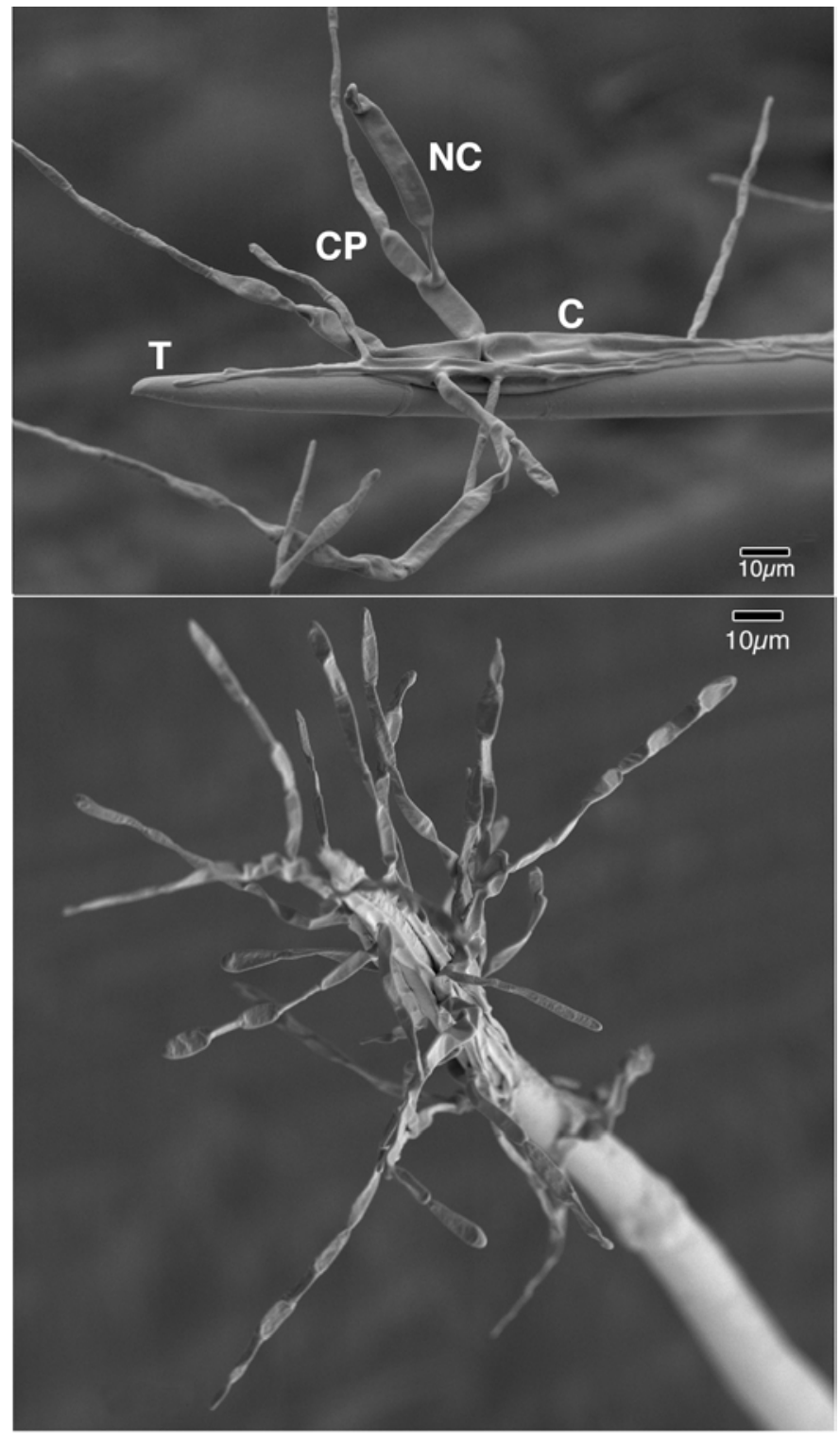

Fig. 1. Scanning electron micrograph of conidia (C) undergoing microcycle conidiation on a maize trichome $(\mathrm{T})$ at $24 \mathrm{~h}$ postinoculation. A new conidium (NC) and conidiophore (CP) are labeled. The lower figure shows production of abundant conidiophores by primary conidia adhering to the tip of a trichome. The conidia and conidiophores have collapsed due to conditions during preparation. Bars represent $10 \mu \mathrm{m}$. 
The ability of $C$. zeae-maydis to produce secondary spores on various substrata was determined by following microcycle conidiation on dry slides in a humid environment and on the surface of water agar, water droplets, and maize trichomes. After 4 days, secondary conidia were produced on all surfaces; however, conidia incubated on dry slides produced approximately 10-fold fewer secondary conidia than those incubated on trichomes (Fig. 3 ). Conidia on water droplets and water agar produced nearly the same amount of secondary conidia.

Influence of exogenous factors. Inhibitors of RNA and protein synthesis affected microcycle conidiation. $\alpha$-Amanitin, which inhibits the synthesis of mRNA, suppressed microcyclic sporulation when applied during the first $6 \mathrm{~h}$ of incubation in a conducive environment (Fig. 4) but did not interfere with germination or germ tube growth. Cycloheximide, a protein synthesis inhibitor, inhibited germination when applied prior to germ tube emergence and halted sporulation when applied at any time during the first $12 \mathrm{~h}$ after deposition of conidia on the droplets (Fig. 4).

Microcycle conidiation did not occur on the leaf surface, and when conidia were deposited directly onto droplets of the leaf washes, microcycle conidiation was inhibited. Colorimetric assays of the water-soluble materials released onto the leaf surface and collected in leaf washes indicated the presence of carbohydrates and amino compounds. Consequently, various nitrogenous compounds and carbohydrates were tested for their effects on microcycle conidiation. Ammonium salts suppressed sporulation but not germination (Fig. 4). Amino acids, nitrate salts, or simple sugars did not affect microcycle conidiation (data not shown). However, hydrogen peroxide solutions inhibited microcycle conidiation at concentrations that allowed spore germination, and this inhibitory effect was reversed by catalase (Fig. 5) and in a separate experiment, it was reversed by peroxidase (data not shown). Likewise, catalase reversed the inhibitory effect of the leaf washes suggesting that hydrogen peroxide may be the component in leaf washes that is responsible for the suppression of microcycle conidiation. Accordingly, attachment to trichomes allows conidia to avoid the inhibitory influences of the water-soluble substances on the leaf surface.

Influence of interrupted periods of wetness and relative humidity. Germinating conidia and those producing conidiophores may dehydrate for a period of time. We observed that, as a droplet evaporated from a slide, conidia dehydrated and adhered to the glass surface. When water was replaced up to a day later, spores rehydrated quickly and resumed growth. Growth of hyphae and development of conidiophores and new conidia on a dry slide

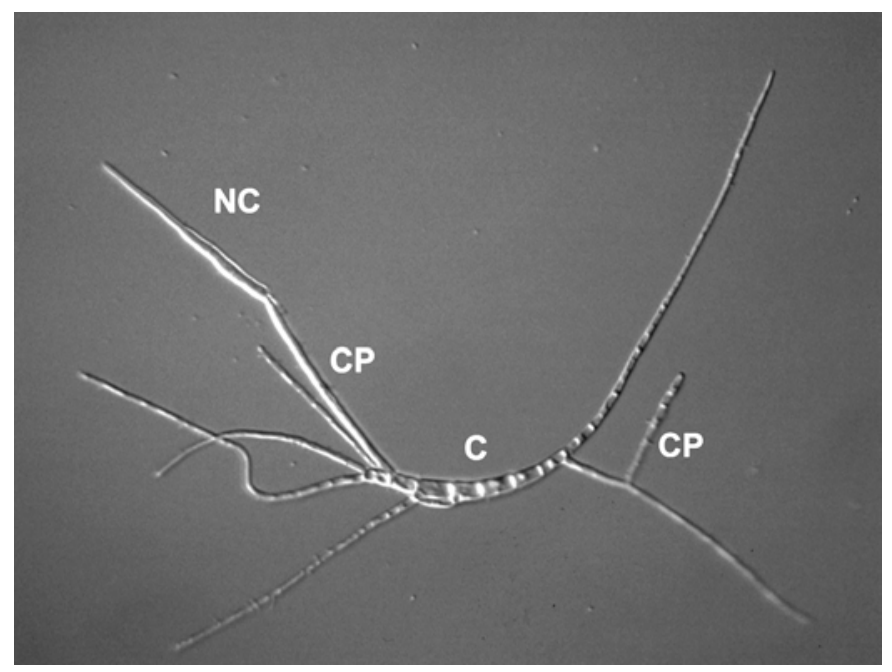

Fig. 2. Microcycle conidiation on a water droplet demonstrating that multiseptate conidiophores $(\mathrm{CP})$ producing new conidia (NC) arise from conidial cells and germ tubes of the original conidium (C). ceased when removed from a humid environment but resumed when returned to a humid environment (Fig. 6).

Relative humidity affected germination and sporulation by spores incubated on a dry slide suspended above a salt solution or water in a sealed container. The conidia germinated in relative humidities from 58 to $100 \%$; however, at relative humidities less than $97 \%$, germ tube growth was minimal and, therefore, secondary conidia were not produced.

As mature conidia and conidiophores dehydrated, cytoplasmic flow into the conidium ceased, and the point of attachment between the conidiophore and the secondary conidium became weak and fragile (Fig. 7). An air stream directed across the slide to simulate wind blowing across a leaf surface detached the dehydrated spores from their conidiophores at wind speeds of approximately $1.3 \mathrm{~m} / \mathrm{s}$. Detachment of hydrated spores required wind speeds of $4.7 \mathrm{~m} / \mathrm{s}$ or more. When dehydrated spores were dispersed onto a water agar plate, they rehydrated, and 90 to $99 \%$ germinated and produced secondary conidia within $24 \mathrm{~h}$. Many of the conidia remaining after repeated application of an air stream were immature. As with many wind-dispersed fungi (42), immature secondary conidia did not detach easily regardless of their hydration status.

\section{DISCUSSION}

The production of spores by the direct formation of conidia without the intervention of mycelial growth has been proposed as a survival mechanism for spores that encounter unfavorable conditions. This process of asexual reproduction has been reported in many fungi, including pathogens such as C. kikuchii (19) and C. beticola (33). Environmental stresses such as high temperature or nutrient limitation are common factors that induce microcycle conidiation. The inhibition of microcycle conidiation in $C$. zeaemaydis by $\alpha$-amanitin suggests that new mRNA must be synthesized for the initiation of conidiophores and formation of secondary conidia, and that this developmental process is programmed during the first $6 \mathrm{~h}$ after inoculation. The inhibition of germination and microcycle conidiation by cycloheximide, regardless of the time of application, suggests that the developmental sequence requires protein synthesis throughout.

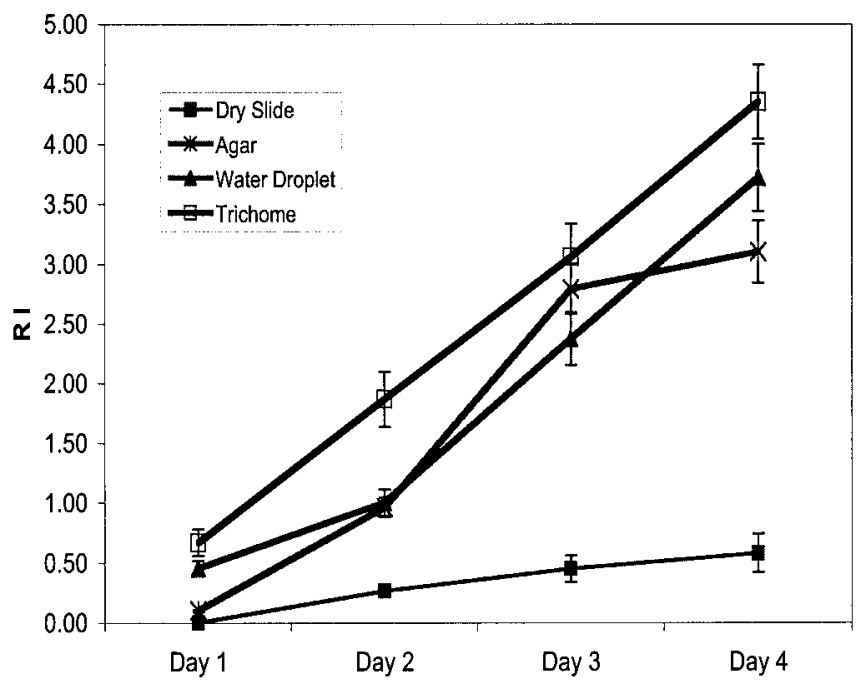

Fig. 3. Effect of various substrata on microcycle conidiation. All treatments were inoculated at the same time and were enclosed in chambers to maintain a relative humidity of approximately 98 to $100 \%$. Conidia on trichomes produced approximately 10 -fold more secondary conidia than those on dry slides. Conidia on water droplets produced slightly more secondary conidia than those on water agar. Values plotted are means of three replicates, and vertical bars indicate the standard deviation at each time period. 
During interactions with potential pathogens and periods of stress, many plants respond by producing active oxygen species and other substances that may have fungistatic or antimicrobial effects $(5,9,10,16,26,28)$. Hydrogen peroxide inhibited microcycle conidiation but not germination of spores on droplets. Catalase reversed the inhibitory effect on microcycle conidiation of hydrogen peroxide and the water-soluble materials in the leaf wash, suggesting that this common plant defense compound may be responsible for the lack of microcycle conidiation when spores are in contact with the leaf surface.

Different forms of nitrogen also can influence the survival, growth, or virulence of fungal pathogens (24). Nitrogen sources, including some that may be present on the leaf surface due to normal metabolism, are known to affect differentiation in some fungi in culture. We observed that microcycle conidiation in $C$. zeae-maydis requires no exogenous nutrient input for up to four generations, and several exogenous factors influence sporulation. Neither nitrate nor amino acids affected microcycle conidiation or germination, but ammonium salts inhibited microcycle conidiation without affecting germination.

In $C$. zeae-maydis, the microcycle conidiation process yielded an average of four secondary conidia per conidium on trichomes, and slightly less on water droplets after 4 days of incubation in a
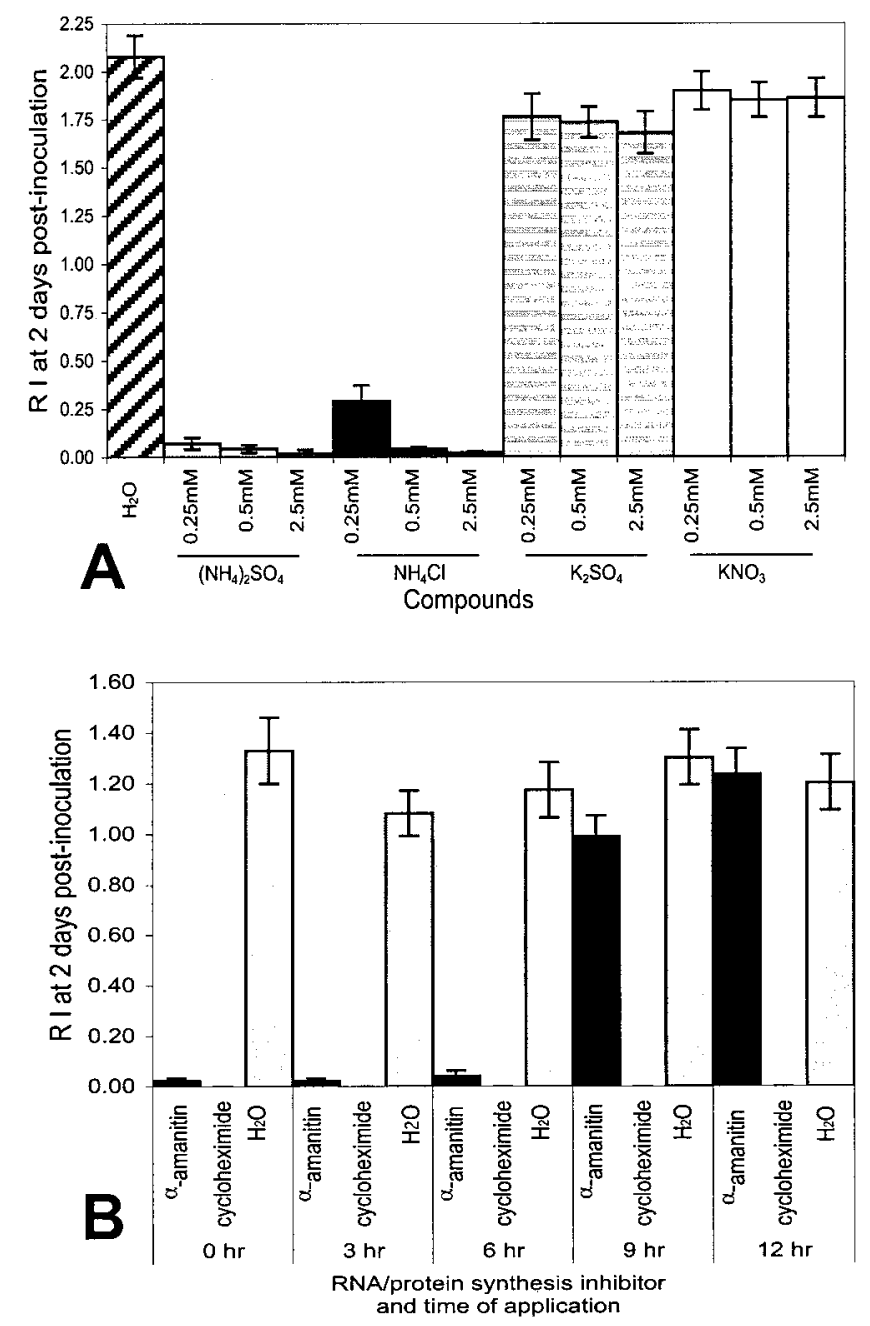

Fig. 4. A, Effects of nitrogen sources or B, RNA and protein synthesis inhibitors on microcycle conidiation. Ammonium sources, but not nitrate or sulfate, suppressed microcycle conidiation. Cycloheximide inhibited microcycle conidiation regardless of the time of application, whereas $\alpha$-amanitin inhibited microcycle conidiation only if applied during the first 6 to $9 \mathrm{~h}$ of development. Columns represent the mean reproductive index of three replicates, and vertical lines indicate the standard deviation for a given treatment. humid environment. Secondary conidia were formed within $24 \mathrm{~h}$ on the surface of a droplet of water. Those conidia that submerged beneath the surface of a droplet germinated but did not produce conidia, indicating that conidia of $C$. zeae-maydis require an airsubstrate interface to produce conidiophores and secondary conidia, or that they were not exposed to light intensity sufficient to induce conidiophore development.

This process occurred on trichomes of many species (data not shown) and required no nutrient input for several generations, suggesting that new inoculum may be generated from conidia that have attached to nontarget plants or surfaces. In the Midwest, soybeans are the crop most commonly rotated with maize and are often planted directly into maize residue. We hypothesize that primary conidia may be dispersed from maize residue in a field to trichomes on soybean or weed species. After a cycle of microcycle conidiation on trichomes, the secondary conidia may be dispersed to other plants or fields to maize leaf surfaces. Because the process requires less than $48 \mathrm{~h}$ to complete, this inoculum and its dispersal may be significant in disease spread and progress.

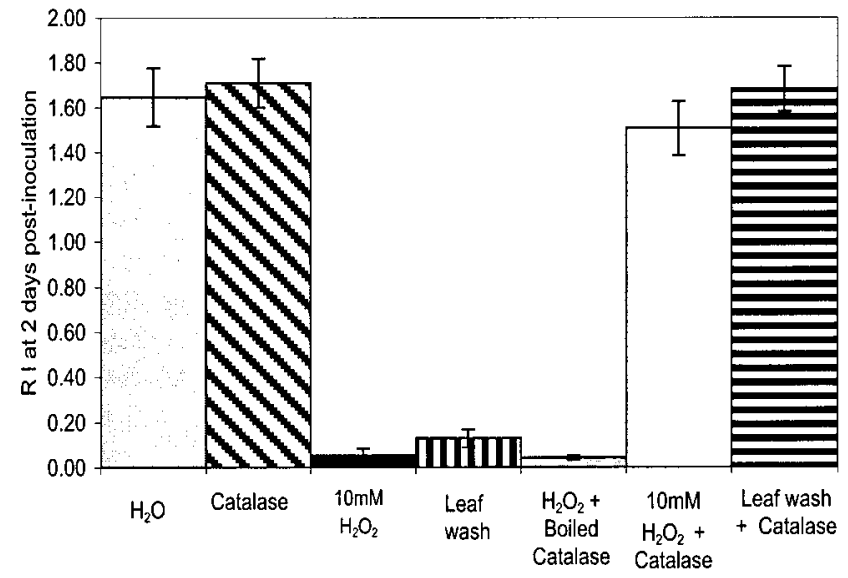

Fig. 5. Inhibition of microcycle conidiation by hydrogen peroxide and watersoluble materials released onto the surface of maize leaves. The inhibitory effect of the leaf wash and hydrogen peroxide was reversed by catalase but not by boiled enzyme. Columns represent the mean reproductive index for three replicates, and vertical lines indicate the standard deviation for each control or inhibitory compound.

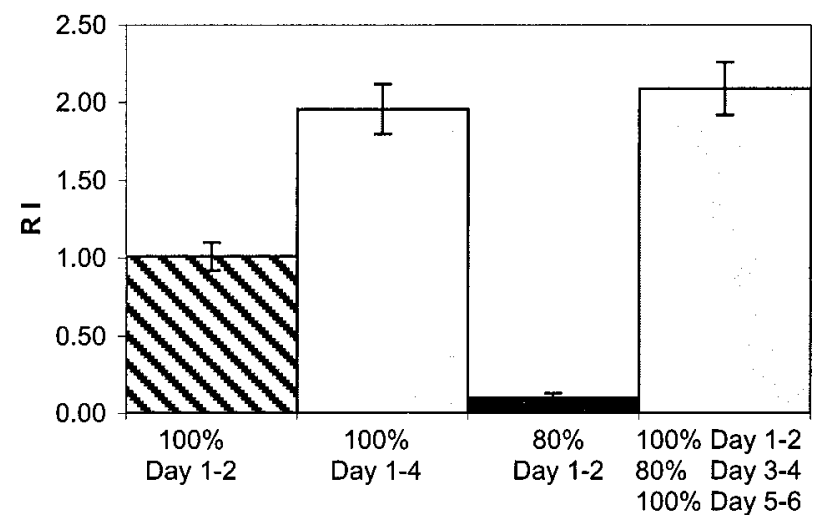

Fig. 6. Effect of an intervening period of dryness on microcycle conidiation. Conidia on dry slides were incubated in sealed chambers maintained at relative humidities of 100 or $80 \%$. Significant microcycle conidiation occurred only at $100 \%$ relative humidity. When conidia, initially incubated for 2 days in $100 \%$ relative humidity, were transferred to $80 \%$ relative humidity for 2 days, production of secondary conidia ceased during that time. However, production of conidiophores and secondary conidia resumed when the conidia were returned to $100 \%$ relative humidity. Data were recorded every $48 \mathrm{~h}$. Columns represent the mean reproductive index for three replicates, and vertical lines indicate the standard deviation for each treatment. 
Further investigation of microcycle conidiation on trichomes resulted in the discovery that relative humidity and intermittent periods of wetness play a significant role in microcycle conidiation. Although germ tube elongation and microcycle conidiation ceased at relative humidities less than $97 \%$, growth resumed when relative humidity again exceeded $97 \%$. The ability to dehydrate and enter a period of quiescence during unfavorable environmental conditions enhances the survival of Cercospora, Botrytis, Monilinia (20,40), and Phytophthora (30) species. Similarly, in accord with the observations of Thorson and Martinson (40), the ability of $C$. zeae-maydis to become developmentally quiescent may assure persistence of inoculum that encounters a host or surface that is not conducive to infection.

We found that as conidiophores and mature conidia dehydrate, the point of attachment becomes fragile, allowing secondary conidia to be more easily detached and dispersed. The data suggest several similarities to observations of Bipolaris maydis; only mature conidia will detach under most conditions, an observation mentioned by Waggoner (42), and hydrated conidia will not detach easily (4). Thus, dry and dehydrated spores are lighter and may travel farther in the wind, and upon landing on target plant surfaces, conidia must be mature to commence germination and further differentiation.

Wind speeds within the maize canopy are generally reported to be less than $3 \mathrm{~m} / \mathrm{s}$ (4). Significantly, dehydrated conidia of $C$. zeae-maydis were detached at wind speeds less than the average canopy wind speed, whereas hydrated conidia were detached by wind speeds greater than that. Therefore, dehydrated conidia are more likely to be dislodged from the leaf and carried farther from the source of inoculum in an air stream $(2,3)$. Dehydrated secondary conidia dispersed by an air stream onto a water agar surface hydrated to their original size and shape, germinated, and produced another generation of secondary conidia. Thus, the secondary conidia are viable, and those carried by wind to the surface of a maize leaf or a trichome may be able to commence growth under favorable conditions. Secondary conidia produced by $C$. beticola were observed to penetrate sugar beet stomata as effectively as original conidia (33). Secondary spores formed by C. zeae-maydis may have a similar efficiency, which would allow

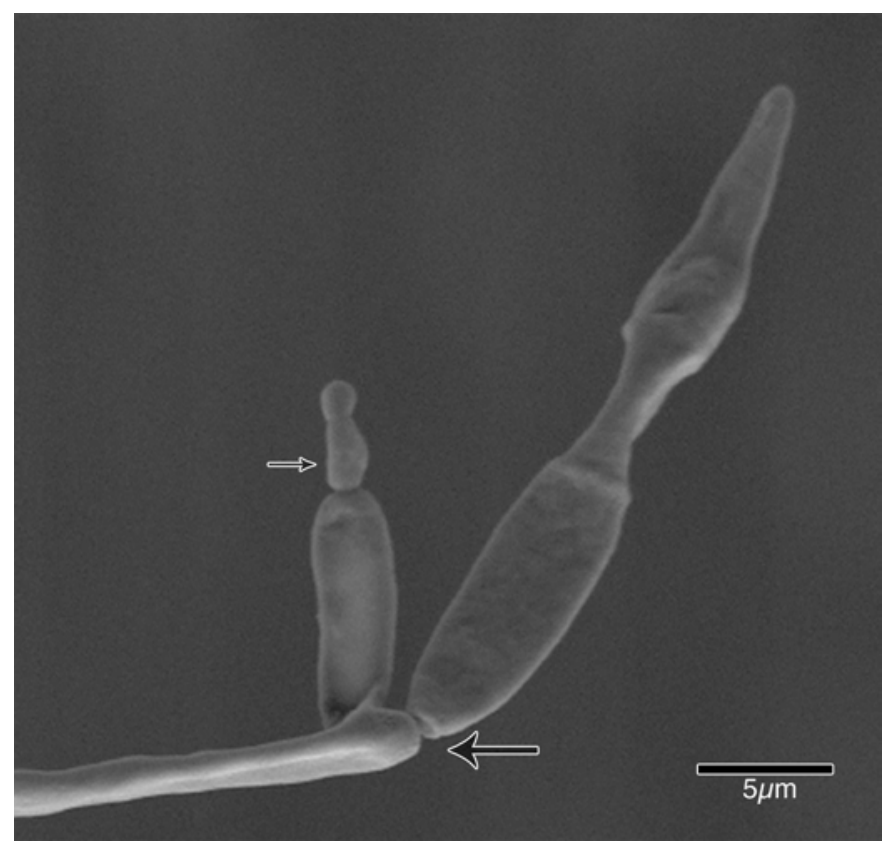

Fig. 7. Scanning electron micrograph showing tenuous connection (large arrow) of mature conidium to the conidiophore. Geniculation of conidiophore and second developing conidium are also shown (small arrow). Bar represents $5 \mu \mathrm{m}$. the fungus to survive unfavorable conditions to be dispersed to a more suitable environment and to infect upon contact of germ tubes with maize stomata.

In this study, we have identified several factors that influence production, detachment, and dispersal of secondary conidia produced through microcycle conidiation. The aspects of microcycle conidiation in C. zeae-maydis observed in this study, as well as those in previous studies of other fungi, contribute to the knowledge of sources of secondary inoculum for gray leaf spot on maize and a more thorough understanding of the disease cycle. This may yield important insights on issues of epidemiological significance and possible control measures for future investigation.

\section{ACKNOWLEDGMENTS}

Research reported is a cooperative investigation of the USDAAgricultural Research Service and the Purdue University Agricultural Experiment Station. Published as paper 16803, Purdue University Agricultural Experiment Station. We thank M. McClenning and D. Sherman for excellent technical assistance.

\section{LITERATURE CITED}

1. Anderson, J. G., and Smith, J. E. 1971. The production of conidiophores and conidia by newly germinated conidia of Aspergillus niger (microcycle conidiation). J. Gen. Microbiol. 69:185-197.

2. Aylor, D. E. 1986. A framework for examining inter-regional aerial transport of fungal spores. Agric. For. Meteorol. 38:263-288.

3. Aylor, D. E. 1990. The role of intermittent wind in the dispersal of fungal pathogens. Annu. Rev. Phytopathol. 28:73-92.

4. Aylor, D. E., and Lukens, R. J. 1974. Liberation of Helminthosporium maydis spores by wind in the field. Phytopathology 64:1136-1138.

5. Baker, C. J., and Orlandi, E. W. 1995. Active oxygen in plant pathogenesis. Annu. Rev. Phytopathol. 33:299-321.

6. Bandyopadhyay, R., Mughogho, L. K., Manohar, S. K., and Satyanarayana, M. V. 1990. Stroma development, honeydew formation, and conidial production in Claviceps sorghi. Phytopathology 80:812818 .

7. Beckman, P. M., and Payne, G. A. 1982. External growth, penetration, and development of Cercospora zeae-maydis in corn leaves. Phytopathology 72:810-815.

8. Beckman, P. M., and Payne, G. A. 1983. Cultural techniques and conditions influencing growth and sporulation of Cercospora zeaemaydis and lesion development in corn. Phytopathology 73:286-289.

9. Cantone, F. A., and Dunkle, L. D. 1990. Involvement of an inhibitory compound in induced resistance of maize to Helminthosporium carbonum. Phytopathology 80:1225-1230.

10. Cantone, F. A., and Dunkle, L. D. 1991. Reversible effects of inhibitory diffusates from maize inoculated with Cochliobolus carbonum. Physiol. Mol. Plant. Pathol. 39:111-122.

11. Chupp, C. 1953. A Monograph of the Fungus Genus Cercospora. Ronald Press Co., Ithaca, NY.

12. Cortat, M., and Turian, G. 1974. Conidiation of Neurospora crassa in submerged culture without mycelial phase. Arch. Microbiol. 95:305-309.

13. Daub, M. E., and Ehrenshaft, M. 2000. The photoactivated Cercospora toxin cercosporin: Contribution to plant disease and fundamental biology. Annu. Rev. Phytopathol. 38:461-490.

14. de Nazareno, N. R. X., Lipps, P. E., and Madden, L. V. 1992. Survival of Cercospora zeae-maydis in corn residue in Ohio. Plant Dis. 76:560-563.

15. de Nazareno, N. R. X., Lipps, P. E., and Madden, L. V. 1993. Effect of levels of corn residue on the epidemiology of gray leaf spot of corn in Ohio. Plant Dis. 77:67-70.

16. Dixon, R. A., Harrison, M. J., and Lamb, C. J. 1994. Early events in the activation of plant defense responses. Annu. Rev. Phytopathol. 32:479501 .

17. Dubois, M., Gilles, K. A., Hamilton, J. K., Rebers, P. A., and Smith, F. 1956. Colorimetric method for determination of sugars and related substances. Anal. Chem. 28:350-356.

18. Dunkle, L. D., and Levy, M. 2000. Genetic relatedness of African and United States populations of Cercospora zeae-maydis. Phytopathology 90:486-490.

19. Fernandez, F. A., Glawe, D. A., and Sinclair, J. B. 1991. Microcycle conidiation and nuclear behavior during conidiogenesis in Cercospora kikuchii. Mycologia 83:752-757.

20. Good, H. M., and Zathureczky, P. G. M. 1967. Effects of drying on the viability of germinated spores of Botrytis cinerea, Cercospora musae, 
and Monilinia fructicola. Phytopathology 57:719-722.

21. Gregory, P. H., and Lacey, M. E. 1963. Liberation of spores from mouldy hay. Trans. Br. Mycol. Soc. 41:449-456.

22. Gwinn, K. D., Stelzig, D. A., and Brooks, J. L. 1987. Effects of corn plant-age and cultivar on resistance to Cercospora zeae-maydis and sensitivity to cercosporin. Plant Dis. 71:603-606.

23. Hanlin, R. T. 1994. Microcycle conidiation-A review. Mycoscience 35:113-123.

24. Huber, D. M., and Watson, R. D. 1974. Nitrogen form and plant disease. Annu. Rev. Phytopathol. 12:139-161.

25. Ingold, C. T. 1971. Fungal spores: Their liberation and dispersal. Oxford, Clarendon Press.

26. Lamb, C., and Dixon, R. A. 1997. The oxidative burst in plant disease resistance. Annu. Rev. Plant Physiol. Plant Mol. Biol. 48:251-275.

27. Latterell, F. M., and Rossi, A. E. 1983. Gray leaf spot of corn: A disease on the move. Plant Dis. 67:842-847.

28. Mehdy, M. C. 1994. Active oxygen species in plant defense against pathogens. Plant Physiol. 105:467-472.

29. Meredith, D. S. 1973. Significance of spore release and dispersal mechanisms in plant disease epidemiology. Annu. Rev. Phytopathol. 11:313343.

30. Minogue, K. P., and Fry, W. E. 1981. Effect of temperature, relative humidity, and rehydration rate on germination of dried sporangia of Phytophthora infestans. Phytopathology 71:1181-1184.

31. Payne, G. A., Duncan, H. E., and Adkins, C. R. 1987. Influence of tillage in development of gray leaf spot and number of airborne conidia of Cercospora zeae-maydis. Plant Dis. 71:329-332.

32. Payne, G. A., and Waldron, J. K. 1983. Overwintering and spore release of Cercospora zeae-maydis in corn debris in North Carolina. Plant Dis. 67:87-89.

33. Rathaiah, Y. 1977. Stomatal tropism of Cercospora beticola in sugarbeet. Phytopathology 67:358-362.
34. Rossier, C., Ton-That, T. C., and Turian, G. 1977. Microcyclic microconidiation in Neurospora crassa. Exp. Mycol. 1:52-62.

35. Rotem, J., and Bashi, E. 1969. Induction of sporulation of Alternaria porri $\mathrm{f}$. sp. solani by inhibition of its vegetative development. Trans. Br. Mycol. Soc. 53:433-439.

36. Rupe, J. C., Siegel, M. R., and Hartman, J. R. 1982. Influence of environment and plant maturity on gray leaf spot of corn caused by Cercospora zeae-maydis. Phytopathology 72:1587-1591.

37. Smith, J. E., Anderson, J. G., Kristiansen, B., Alrawi, A., and Yahya, A.G. 1981. Microcycle conidiation. Pages 627-650 in: The Fungal Spore: Morphogenic Controls. G. Turian and H. R. Hohl, eds. Academic Press, London.

38. Stavely, J. R., and Nimmo, J. A. 1968. Relation of $\mathrm{pH}$ and nutrition to growth and sporulation of Cercospora nicotianae. Phytopathology 58:1372-1376.

39. Tehon, L. R., and Daniels, E. 1925. Notes on the parasitic fungi of Illinois. Mycologia 17:240-249.

40. Thorson, P. R., and Martinson, C. A. 1993. Development and survival of Cercospora-zeae-maydis germlings in different relative-humidity environments. Phytopathology 83:153-157.

41. Tuite, J. F. 1969. Page 218 in: Plant Pathological Methods; Fungi and Bacteria. Burgess Publishing Co., Minneapolis, MN.

42. Waggoner, P. E. 1973. The removal of Helminthosporium maydis spores by wind. Phytopathology 63:1252-1255.

43. Ward, J. M., Liang, M. D., and Rijkenberg, F. H. J. 1997. Frequency and timing of fungicide applications for the control of gray leaf spot in maize. Integr. Pest Manage. Rev. 3:1-12.

44. Ward, J. M., Stromberg, E. L., Nowell, D. C., and Nutter, F. W., Jr. 1999. Gray leaf spot. A disease of global importance in maize production. Plant Dis. 83:884-895.

45. Yemm, E. W., and Cocking, E. C. 1955. The determination of amino acids with ninhydrin. Analyst 80:209-213. 